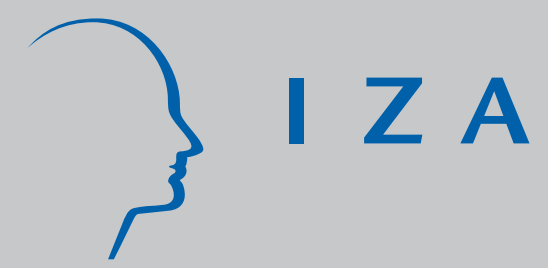

IZA DP No. 5526

Long-term Effects of Early Childhood Malaria Exposure on Education and Health: Evidence from Colonial Taiwan

Simon Chang

Belton Fleisher

Seonghoon Kim

Shi-yung Liu

February 2011 


\title{
Long-term Effects of Early Childhood Malaria Exposure on Education and Health: Evidence from Colonial Taiwan
}

\author{
Simon Chang \\ Central University of Finance and Economics \\ Belton Fleisher \\ Ohio State University, \\ Central University of Finance and Economics, and IZA \\ Seonghoon Kim \\ Ohio State University \\ Shi-yung Liu \\ Academia Sinica
}

Discussion Paper No. 5526

February 2011

IZA

P.O. Box 7240

53072 Bonn

Germany

Phone: $+49-228-3894-0$

Fax: +49-228-3894-180

E-mail: iza@iza.org

Any opinions expressed here are those of the author(s) and not those of IZA. Research published in this series may include views on policy, but the institute itself takes no institutional policy positions.

The Institute for the Study of Labor (IZA) in Bonn is a local and virtual international research center and a place of communication between science, politics and business. IZA is an independent nonprofit organization supported by Deutsche Post Foundation. The center is associated with the University of Bonn and offers a stimulating research environment through its international network, workshops and conferences, data service, project support, research visits and doctoral program. IZA engages in (i) original and internationally competitive research in all fields of labor economics, (ii) development of policy concepts, and (iii) dissemination of research results and concepts to the interested public.

IZA Discussion Papers often represent preliminary work and are circulated to encourage discussion. Citation of such a paper should account for its provisional character. A revised version may be available directly from the author. 
IZA Discussion Paper No. 5526

February 2011

\section{ABSTRACT}

\section{Long-term Effects of Early Childhood Malaria Exposure on Education and Health: Evidence from Colonial Taiwan}

We estimate the effects of early childhood malaria exposure on education and health at older ages by exploiting variations in malaria exposure risk around birth that resulted from a universal malaria eradication campaign in colonial Taiwan in the early $20^{\text {th }}$ century. We find that malaria exposure around birth leads to lower life-time educational attainment and to worse mental and physical health outcomes in old age as reflected in particular in worse cognitive function, a higher likelihood of cardiovascular diseases and a higher mortality hazard, compared to those who were not exposed.

JEL Classification: I12, I18, I21, O15, O18

Keywords: malaria, early childhood, education, health, Taiwan

Corresponding author:

Belton M. Fleisher

Department of Economics

Ohio State University

410 Arps Hall

1945 N. High Street

Columbus, $\mathrm{OH} 43210$

USA

E-mail: fleisher@econ.ohio-state.edu 


\section{Introduction}

Epidemiological studies suggest that health shocks in utero or in early childhood may lead to serious long-term health consequences. For example, it is known that if a young child lacks sufficient oxygen and nutrients—due to malaria for example — that are essential for brain development, long-term impairment of cognitive functions may follow (Holding and Snow 2001). Similarly, shocks prior to birth, such as fetal malnutrition as postulated in the fetal-origins hypothesis, can permanently change the physiology and metabolism of the fetus, leading to chronic conditions in adulthood such as cardiovascular diseases (Barker 1992, 1993, 1994, 1995). ${ }^{1}$

A major problem for researchers in attempting to empirically establish such longterm causal relationships is that omitted or unobserved factors may influence both earlylife health measures and subsequent outcomes. A distinguishing feature of our research is that we exploit information on exogenous changes in the disease environment into which individuals were born to identify the effects of early childhood health shocks on education and various health outcomes at older ages. Specifically, we utilize variations in malaria exposure risk around birth that resulted from a universal malaria eradication campaign in colonial Taiwan in the early $20^{\text {th }}$ century. By malaria exposure risk, we mean that we estimate the impact of the likelihood of contracting malaria, rather than that of actually contracting malaria infection.

Our paper adds to the growing literature that treats the relationships between early-life health shocks and adult outcomes (Almond and Mazumder 2005; Almond 2006; Almond et al. 2007; Chen and Zhou 2007; Almond et al. 2009; Case and Paxson 2009;

\footnotetext{
${ }^{1}$ The fetal-origins hypothesis was proposed by British physician David Barker based on his series of studies in the 1990s. The hypothesis has been tested by numerous empirical studies in epidemiology. See Rasmussen (2001) for a review.
} 
Meng and Qian 2009; Barreca 2010; Bleakley 2010; Case and Paxson 2010; Cutler et al. 2010; Kim et al. 2010; Lucas 2010). Our findings show that higher malaria exposure risk around birth leads to lower life-time educational attainment and to worse health outcomes in old age. In particular, we find that elderly people who were exposed to a high malaria risk prior to or around their birth dates tend to have worse cognitive functions, are more likely to have high blood pressure and heart problems, and that they experience a higher mortality hazard. Our findings on health outcomes in old age support the fetal-origins hypothesis.

Several recent studies have investigated the long-term effects of malaria exposure in childhood (Barreca 2010; Bleakley 2010; Cutler et al. 2010; Lucas 2010). Overall, they find that malaria exposure in childhood leads to lower education and economic status in adulthood. Our research contributes to the existing literature by further investigating the effect of early-life malaria exposure on health outcomes in old age. Bleakley (2010) points out that malaria eradication can increase both the benefit and the opportunity cost of investment in education, implying an ambiguous effect on education. Although health is partly affected by choices made over the life cycle, we postulate that acquired health problems are less easy to overcome than early schooling disadvantages. Thus, health outcomes are arguably better measures than education outcomes for observing the causal impact of malaria eradication.

The rest of this paper is organized as follows. In the next section, we introduce the malaria eradication campaign in colonial Taiwan. Section three presents our empirical strategy and identification. In the fourth section, we describe our data. Section five contains our estimation results. We conclude in section six. 


\section{Malaria Eradication in Colonial Taiwan}

Malaria is an infectious disease caused by Plasmodium, a parasite generally transmitted via bites of female Anopheles mosquitoes. ${ }^{2}$ However, it can also be vertically transmitted from an infected mother to her fetus, causing so-called congenital malaria. ${ }^{3}$ Once transmitted into the human body, the parasites reproduce in the liver and then destroy red blood cells, eventually causing fever, headache, vomiting, malnutrition, anemia, enlarged spleen, and even death. People with lower immunity such as infants and pregnant women are at the highest risk of malaria infection (WHO 2010).

In the early stage of the period of the Japanese rule (1895-1945), malaria was not only rampant but also deadly in Taiwan. ${ }^{4}$ Between 1906 and 1909, for example, more than 10,000 residents died of malaria each year, while the population was only about 3 million (Department of Health, Taiwan 1991). To fight against malaria, the Japanese colonial government initiated an island-wide eradication campaign in 1911, which lasted until the eruption of World War II (Ting 2008; Ku 2010; Liu 2010). ${ }^{5}$ In 1911, an islandwide monitoring system was established. All malaria cases had to be reported to local

\footnotetext{
${ }^{2}$ There are four strains of Plasmodium that are known to infect humans: P. falciparum, P. vivax, P. ovale, and $P$. malariae. However, only $P$. falciparum is fatal (WHO). (Information is available at http://who.int/topics/malaria/en/ .)

${ }^{3}$ Recently, congenital malaria cases have been increasingly detected in endemic countries (Manendez and Mayor 2007; Poespoprodjo et al. 2010). In addition, although less commonly, malaria could be transmitted through blood transfusion and needle sharing, too.

${ }^{4}$ It is worth noting that malaria was not the only infectious disease in the colonial period. Others include plague, dysentery, cholera etc. However, malaria was the most prevalent and deadliest one. For example, in 1902, malaria caused 13,444 deaths, while plague only caused 1,853 deaths, dysentery 754 and cholera 613 (Yearly Statistics Book of the Office of the Governor-general in Taiwan 1903). Besides, plague had been under control by 1910 and was eradicated in 1917, while dysentery and cholera never became island-wide endemic (Tetsuzou 2007).

${ }^{5}$ The Governor-general, head of the colonial government, convened a meeting on malaria in 1911 and promulgated a series of anti-malaria laws in 1913 (Ku 2010; Liu 2010). In fact, there were some pilot programs in scattered places before 1910 (Ting 2008).
} 
physicians by the police and the local self-policing system. ${ }^{6}$ So-called anti-malaria districts were gradually set up throughout the whole island. The number of anti-malaria districts increased from 12 in 1911 to 185 in 1942 (Liu 2010). Prior to 1919, only residents within the districts were required to provide blood smears in order to test for malaria and, if found to carry Plasmodium, they were forced to take quinine- - used as a cure as well as a prophylaxis during the colonial period—for 18 days under the supervision of a policeman. In 1919, the campaign expanded to include areas beyond the districts and emphasized vector-control measures such as cleaning up the environment to reduce the breeding of mosquitoes. Meanwhile, blood tests and quinine prophylaxis continued. $^{7}$

Three groups played major roles in carrying out eradication measures: (i) the public health physicians, (ii) the police, and (iii) the local self-policing system. The main duty of the public health physicians was to inspect and prevent malaria and write reports to the colonial government (Tetsuzou 2007). The police supervised the blood tests, quinine treatment, and environment cleaning. The local self-policing system was to help the police carry out the measures and to report any suspected cases of malaria (Ting 2008; Ku 2010).

Malaria distribution in the colonial period varied considerably from north to south. Located off the coast of southeast mainland China, Taiwan is a mountainous island stretching 240 miles from north to south and 90 miles from east to west at its widest point. Its climate features subtropical to tropical temperatures with excessive humidity, which is

\footnotetext{
${ }^{6}$ The self-policing system was called Bao Jia in Chinese. Bao was a unit of 10 households and Jia was a unit of 100 households. The system was organized for security purpose by households in local communities. ${ }^{7} \mathrm{Ku}$ (2010) points out that an unexpected rise in malaria in the mid-1910s made the colonial government determined to expand the campaign and pay more attention to environmental controls. In response, a series of new anti-malaria laws was enacted in 1919.
} 
conducive to the breeding of mosquitoes. Figure 1 shows the five prefectures in colonial Taiwan in 1920, with darker areas characterized by greater malaria severity in terms of death rates. ${ }^{8}$ As illustrated, malaria was generally more serious in the south than in the north. Figure 2 shows the trend of malaria death rates for all Taiwan and for each prefecture. ${ }^{9}$ After the eradication campaign was initiated in the early 1910 s, the malaria death rate dropped dramatically from 4 deaths per 1,000 people in the early 1910s to less than 1 in the late 1920s, remaining under control through the 1930s. ${ }^{10}$ The Nankao prefecture in the south experienced the biggest drop in malaria, and the north-south disparity disappeared in the 1930s. We attribute this elimination of regional disparity to the malaria eradication campaign.

\section{Empirical Strategy and Identification}

We acknowledge that it is malaria infection, rather than exposure risk, that can affect subsequent outcomes. However, we assume that there exists a stable stochastic relationship between malaria infection and exposure risk. We focus on malaria exposure risk at the prefecture level in the year of birth and the year before birth, because during these two years, a child could possibly contract malaria in utero or directly via mosquito

\footnotetext{
${ }^{8}$ The size of each prefecture is roughly equivalent to 2-3 counties today. Nankao in the south and Huadong in the east each actually consist of two prefectures in 1920. Between 1901 and 1941, there were two changes in administrative divisions, one in 1909 and the other in 1920. The changes make the prefecturelevel data not comparable for these prefectures. Hence, we merge these prefectures together to make historical data comparable across years. For convenience, we still call them a prefecture. ${ }^{9}$ Malaria death rates are authors' own calculation using statistics from various Yearly Statistics Books of the Office of the Governor-general in Taiwan published by the colonial government.

${ }^{10}$ It is worth noting that malaria was not completely eradicated by the end of the colonial period (Ku 2010). The eruption of World War II (WWII) curtailed the eradication campaign and malaria burst out again. The Chinese Nationalist government took over Taiwan after WWII and initiated another eradication campaign in the 1950s with the help of dichloro-diphenyl-trichloro-ethane (DDT), which was not available in the colonial period. In 1965, the World Health Organization (WHO) finally declared Taiwan as malaria-free.
} 
bites after birth. Later in section 5.3, we also show that the malaria effects in these two years are more critical than other ages.

Our benchmark model is

(1)

$$
y_{i p t}=\beta \text { Exposure }_{p t}+\alpha_{p}+\gamma_{c}+\alpha_{p} \times \gamma_{c}+\theta X_{i p t}+\varepsilon_{i p t},
$$

where

- $i$ denotes an individual; $p$ denotes prefecture of birth; $t$ denotes year of birth; $c$ denotes a grouped birth-cohort; we group individuals into four roughly-10-year birth cohorts; ${ }^{11}$

- $y$ is an individual outcome variable;

- Exposure is prefecture-level malaria exposure risk;

- $\quad \alpha$ is a prefecture fixed effect;

- $\quad \gamma$ is a grouped birth-cohort fixed effect;

- $\quad X$ is a vector of controls including sex, ethnicity, family background, prefecture-level economic and education resource indicators that are time-varying; ${ }^{12}$ and

- $\varepsilon$ is an error term that may be correlated across individuals who were born in the same prefecture and year.

The parameter $\beta$ measures the average change in an individual outcome in later life as a response to an increase in malaria exposure risk by one unit. In the vector $X$, we

\footnotetext{
${ }^{11}$ We divide our sample into four grouped birth cohorts: 1901-1908, 1909-1919, 1920-1929 and 1930-1941. The choice of the cut-off points is based on the following. First, there were two administrative division changes in 1909 and 1920 respectively. According to Liu (2010), changes in administrative division had significant implication on redistribution in resources in preventing malaria. Second, the eradication campaign went through a major overhaul in 1919. Third, Ku (2010) points out that the period of 1930s is another phase in the eradication campaign that was different from the previous phases. These changes suggest that the time trend for these four periods could be different. We thus include the grouped birth cohort fixed effect accordingly.

${ }^{12}$ We include father's education and occupation to control for family background. Taiwan was an agricultural economy in the colonial period. To measure prefecture-level economy, we use the output of rice and sugar cane, which were the two most important agricultural products then. Moreover, we include the number of primary schools in the prefecture to control for local educational resources.
} 
control for prefecture-level economic and education resource indicators that may have influenced both malaria exposure risk and individual outcomes. We account for unobserved aggregate variables whose omission may lead to biased estimates by including dummy variables to represent prefecture fixed effect, grouped birth-cohort fixed effect and their interaction term.

Our major econometric challenge is that we must infer the risk of malaria exposure from observed malaria death rates, which are the best information available to us. One might model the true risk as a function of many factors such as nearby malaria hosts, mosquitoes, parasites, medical facilities, government intervention, mother's immunity, and other environmental and individual characteristics. Many of these factors are not observed, and the exact modeling of their interaction is unknown. Thus, we assume that malaria death rates are proportional to the risk and therefore we use malaria deaths per 1,000 individuals at the prefecture level as a proxy for malaria exposure risk. More explicitly, we assume the stochastic relationship between malaria death rates and malaria exposure is as follows.

(2) Malaria $_{p t}=\delta$ Exposure $_{p t}-\eta_{p t}$,

where Malaria is malaria deaths per 1,000 individuals; $\delta$ is a proportionality coefficient; $\eta$ is an unobserved measurement error; other notations are the same as before. Following the classical errors-in-variables assumption, we assume Exposure and $\eta$ are uncorrelated. Plug (2) into (1) and after some arrangements we can get an operational benchmark model as follows.

(3) $y_{i p t}=\lambda$ Malaria $_{p t}+\alpha_{p}+\gamma_{c}+\alpha_{p} \times \gamma_{c}+\theta X_{i p t}+\lambda \eta_{p t}+\varepsilon_{i p t}$, where $\lambda=\beta / \delta$. 
The parameter $\lambda$ now measures the average change in an individual outcome in later life as a response to one additional malaria death per 1,000 people in the prefecture of birth in the year of birth and the year before birth. (Peak death rates were about 4 deaths per 1,000 in the colonial period.) However, under the classical errors-in-variables assumption, Malaria and $\eta$ must be correlated, leading to a biased estimate of $\lambda$.

\section{Measurement errors}

In addition to simple observation errors, measurement errors could arise for two reasons. First, malaria death rates may deviate away from proportionality to exposure risk due to unobserved factors. For example, three parasite strains were found among malaria patients in colonial Taiwan: P. falciparum, P. vivax and P. malariae (Sawa 1931; Morishita 1976). Of these, only P. falciparum would typically cause mortality, but all three strains could cause morbidity. The parasites composition could vary geographically and over time. Second, measurement errors could arise from mis-identification of birth place for one-third of our sample, as indicated below. Although both types of measurement error could lead to biased estimates of the malaria exposure effects, we argue later that the second cause of measurement errors is less a concern than the first.

\section{Instrumental Variables}

We address the first cause of measurement error with an instrumental variables (IV) approach, in which two prefecture-level variables are used to instrument for the malaria death rates. These two variables are (i) the number of public health physicians per 10,000 people and (ii) the number of other medical personnel-including physicians, pharmacists and midwives-per 10,000 people, both variables measured in the year of birth. 
For these two variables to be valid instruments, these medical professionals must be correlated with the true malaria exposure risk but uncorrelated with the unobserved measurement errors. The most plausible violation of the latter requirement is that the Japanese colonial government assigned the medical professionals ex post to a certain prefecture based on local malaria death rates. However, while all these medical professionals were regulated by the colonial government, only public health physicians were assigned by the colonial government. ${ }^{13}$ According to related official documents in the colonial period, the assignments of the public health physicians were mainly based on the local medical care resources and population density rather than malaria death rates. ${ }^{14}$ Later, we also provide an over-identification test to test for the exogeneity of our instruments.

It is plausible that the presence of these medical professionals in each prefecture reduced malaria exposure risk by contributing in malaria prevention or treating malaria patients, who host the malaria parasites. ${ }^{15}$ In fact, our first-stage estimation results later show that the medical professionals are significantly negatively correlated with malaria death rates.

\section{Watershed versus Wiggle Effect}

From the perspective of policy makers, it would be interesting and important to learn the full benefit of the eradication campaign by utilizing the full variation in malaria during the colonial period. For example, if the malaria deaths per 1,000 people drop from 4

\footnotetext{
${ }^{13}$ All medical personnel were regulated by the colonial government through licensing (Lo 2002). However, medical professionals, except for public health physicians, could choose where to practice.

${ }^{14}$ The related official documents in the colonial period include Public Health Physicians Regulation (1896) and Document on the Assignment of Public Health Physicians (1898) (both are in Japanese).

${ }^{15}$ Public health physicians' main duty was to inspect and prevent infectious diseases, including malaria. Usual physicians were the main medical force to treat malaria patients. In addition, pharmacists and midwives could provide quinine and other fever-reducing medication to cure malaria patients and kill malaria parasites.
} 
(before the campaign) to 0 (after the campaign), an ideal estimate of the full benefit of the eradication would be the difference in a later-life outcome between people who were born into the high-risk environment (where malaria death rates are four per thousand) and those who were born into the low- risk environment (where malaria death rates are virtually zero), provided that all else were equal. We use Bleakley's term to dub this the watershed effect. ${ }^{16}$ However, we do not attempt to estimate the watershed effect, because colonial Taiwan experienced rapid social and economic transitions in many other aspects during the period of malaria eradication, such as infrastructure, public health system, which were likely correlated with malaria reduction. We do control for these transitional effects by adding grouped cohort and prefecture dummy variables, but as a result, we are left with residual variations in malaria that remain after holding constant the variation associated with these dummy variables. In other words, we can only exploit the "wiggles" within the overall declining trend of malaria exposure risk to estimate the various effects of malaria, which as Bleakley dubs it, is the wiggle effect.

\section{Data}

We employ historical data on malaria death rates, population, public health physicians, medical personnel, other education and economic variables in the colonial period from various Yearly Statistics Books of the Office of the Governor-general in Taiwan published by the colonial government. ${ }^{17}$ Because malaria death information is only available for the period 1901-1941, we restrict our study period accordingly. Two key malaria variables are defined as follows. MALARIA1 is the malaria deaths per 1,000

\footnotetext{
${ }^{16}$ We thank Hoyt Bleakley for suggesting these terms to us as well as his other valuable comments.

${ }^{17}$ An online archive of the Yearly Statistics Books of the Office of the Governor-general in Taiwan is available at http://tcsd.lib.ntu.edu.tw/.
} 
people in the year of birth, and MALARIA2 is the average malaria deaths per 1,000 people in the year of birth and the year before birth. Both are measured at the prefecture level. For more details about historical data, see Appendix 1.

The micro-level data come from a longitudinal survey—Survey of Health and Living Status of the Middle-aged and the Elderly in Taiwan. This survey was initiated in 1989 using a representative sample of the elderly aged 60 and older. In 1996, it drew another sample representing the middle-aged population between 55 and 66. We combine these two samples and discard those who were not born in Taiwan to form our main analysis sample. Our final analysis sample consists of 4,575 people who were born during 1901 and 1941.

An advantage of our data is that we have exact birth place information for two thirds of our sample. For the remaining one third, we use current residence as the measure of birth place. We believe current residence is a reasonable proxy for birth place based on robustness checks reported later in our empirical results. ${ }^{18}$

Our sample consists of malaria survivors, and a selectivity problem must be considered. If the survivors and those who died of malaria in early childhood were different in some unobserved aspects that are also correlated with the later-life outcomes, our estimation results will be biased. For example, it is possible that people with higher innate ability are more likely to survive malaria as well as to have more education attainment. In this case, we are likely to underestimate the malaria effect. We are not able to correct for such selection bias, since we do not observe the dead. However, we suspect that the selection bias attenuates the true malaria effect, thus is against rejecting the null

\footnotetext{
${ }^{18}$ We know both the birth place and current residence for the elderly people born between 1901 and 1929 (66\% of the sample), while we only know their current residence for those born between 1930 and 1941 (34\% of the sample).
} 
of no malaria effect. We consider our estimate as a lower-bound estimate of the true malaria effect.

Moreover, since we use a sample of individuals in later life, we do not observe those who died before they could appear in our data. For the same reasons stated above, we believe that the resulting bias is against rejecting the null of no malaria effect. As a robustness check for the possible selection bias due to pre-observation deaths, we also estimate our models with census data, which are more "representative” of the cohorts born in the colonial period. We use the 1980 census - the earliest census available in electronic form in Taiwan—that consists of all individuals born 1901-1941 who were still alive in 1989 and is thus more "representative" than our analysis sample. A disadvantage is that the census only provides limited information on education and current residence.

\section{Estimation Results}

\subsection{The Effect of Malaria Exposure on Education}

We look at two education outcomes (Table 1). One is a dummy variable indicating whether one received any schooling (Panel A). The other is a continuous variable for years of schooling, including no schooling (Panel B). 51\% of the individuals in our sample (born 1901-1941) obtained some schooling and the average schooling is about 3.39 years. These schooling levels reflect how limited access to education was during the colonial period in Taiwan.

OLS estimation results

In Panel A, the results suggest that one less malaria death per 1,000_equivalent to $25 \%$ of the total reduction in the colonial period-is associated with an increase of $3 \sim 6$ 
percentage points in the probability of receiving any schooling. In Panel B, the results imply one less death per 1,000 is associated with an increase of .1 .5 years in the average years of schooling. The results are generally statistically significant at the $5 \%$ level, except for the two cases in Panel B that do not include interaction terms of the prefecture dummies and the grouped birth-cohort dummies. ${ }^{19}$ The estimates are generally larger and more statistically significant when interaction terms are included, and this suggests the existence of differential grouped birth-cohort effects.

OLS estimates show that malaria exposure risk in the early life is negatively associated with education outcomes in later life. However, measurement error and other types of unobserved heterogeneity can confound identifying the true causal effect on the basis of the OLS estimates. In the following subsections, we check whether our baseline results are robust to alternative estimation strategies.

\section{Robustness check for birth place and current residence}

To check whether our estimation results are sensitive to our use of current residence as a proxy for birth place, we make use of the sample of individuals born between 1901 and 1929, for whom we know both place of birth and current place of residence. ${ }^{20}$ About $14 \%$ of them report that they were born in a different prefecture during the colonial period. Table 2 shows the results of re-estimating the regressions reported in Table 1 for this sample. In this smaller sample, about $44 \%$ of the individuals attended at least one year of school, and average schooling is 2.9 years. The estimated coefficients of malaria death rates appear to be quite robust whether malaria death rates are defined by birth prefecture or by current residence prefecture.

\footnotetext{
${ }^{19}$ We use robust standard errors clustered at birth year and prefecture.

${ }^{20}$ A better check would look at the migration around birth. However, we do not have such information.
} 
Two-stage Least Squares (2SLS) estimation

We next use two-stage least squares (2SLS) as an additional check on the robustness of our estimates to the use of death rates as a proxy for exposure to the risk of contracting malaria. We instrument the death rates with variables representing the number of public health physicians and the number of other medical personnel. As stated above, our identifying assumption is that these medical professionals were correlated with malaria exposure risk but uncorrelated with the measurement errors.

Figure 3 and 4 show the number of public health physicians and other medical personnel per 100,000 in the colonial period. Both series rise over time, while the malaria death rate declined. The sharp increase in the number of public health physicians in the early 1920s reflects the expansion of the eradication campaign at that time.

In Figure 5 we show the partial correlation between residuals obtained by regressions of our two measures of malaria death rates and by regressions of our instrumental variables on other regressors in equation (3). ${ }^{21}$ The four graphs illustrate a pronounced negative correlation between the malaria death rates and the instrumental variables.

First-stage estimation results

In Panel A of Table 3 we show respectively the results of regressing MALARIA1 on each of the two medical personnel instruments separately and on both of them together. All regressions include all the other exogenous variables in equation (3). In Panel B we

\footnotetext{
${ }^{21}$ We use four residual variables. First, we regress MALARIA1 and MALARIA2 separately on the full set of right-hand-side control variables in equation (3) except for the malaria variables themselves and get two residual variables, which reflect the part of MALARIA1 and MALARIA2 that are not explained by the control variables. Second, we regress the two instrumental variables separately on the same set of control variables and get another two residual variables, which reflect the part of the instrumental variables that are not explained by the control variables. We then plot the malaria death rate residuals against the instrumental variables residuals, which show the partial correlation between the malaria death rates and the instrumental variables.
} 
show the comparable estimation results for MALARIA2. All the estimated coefficients for the medical personnel variables are negative and statistically significant. The partial F statistics test the joint significance of these instrumental variables, and these statistics support that our instrumental variables are strong instruments. Second-stage estimation results of malaria exposure risk on education

The second stage results are reported in Table 4 . All regressions include the full set of controls, identical to the specification in columns (3) and (6) of Table 1. We test whether our instrumental variables are exogenous using the Basmann $\chi^{2}$ test. The test statistics are reported in columns (3) and (6) where both instrumental variables are used, and the $\chi^{2}$ statistics do not reject the null hypothesis that both instrumental variables are exogenous.

In panel A, the 2SLS results imply that one less malaria death per 1,000 would increase the probability of receiving any schooling by 13 to 20 percentage points, roughly 3 to 4 times the magnitudes of the OLS estimates. ${ }^{22}$ The big difference between the OLS estimates and the 2SLS estimates is consistent with our suspicion that death rates measure malaria exposure risk with errors, leading to classical measurement-error bias in OLS regressions. In Panel B, the results imply that one less malaria death would increase average years of schooling by between 1.4 and 1.5 years, again 3 to 4 times the magnitudes of the OLS estimates. ${ }^{23}$ These results offer strong support for the hypothesis that the negative effects of the malaria exposure in early life are persistent and sizeable. Are our estimation results biased by unobserved mortality?

\footnotetext{
${ }^{22}$ Compare to the results in column (3) and (6) in Panel A of Table 1.

${ }^{23}$ Compare to the results in column (3) and (6) in Panel B of Table 1.
} 
A possible source of bias in our estimates arises in our inability to observe the characteristics of individuals who died before they could be observed in our data. As a robustness check, we use the 1980 census - as mentioned in the data section, it is more "representative" of the cohorts born in the colonial period - to re-estimate the malaria exposure effect on education. ${ }^{24}$ The OLS results are reported in Panel A of Table 5, while the 2SLS results are reported in Panel B. The dependent variable is the dummy variable indicating whether an individual received any schooling. The OLS regression results from the Census data are consistent both in signs and sizes with the results obtained from our original panel data. The 2SLS results are also consistent in sign and are slightly larger than those obtained from our panel data.

\subsection{The Effects of Malaria Exposure on Health in Later Life}

We use three measures of health outcomes in later life: cognitive functions, cardiovascular diseases and mortality. While we have mortality information for every individual in the sample, our measures of other health outcomes are affected by sample attrition due to mortality. Our measures of cognitive functions and cardiovascular diseases are taken in 1996, when the cohort born 1930-1941 first appeared in the elderly panel survey. However, 1,000 of the elders born 1901-1929 were not interviewed in 1996, mainly due to mortality. ${ }^{25}$ Thus, the final sample for the analysis of cognitive functions and cardiovascular diseases consists of 3,575 individuals. A related selection bias due to mortality is that those who remained alive in 1996 may have higher innate ability to resist

\footnotetext{
${ }^{24}$ We restrict to those who were born during 1901-1941 in Taiwan. The final sample consists of 4,436,007 individuals. Education information in the census data is categorical, which prevents us from calculating the exact years of schooling. Hence, we only estimate the effect on the probability of receiving any schooling. In addition, the census also lacks information on ethnicity, father's education and occupation. We thus do not include these two in the regressions.

${ }^{25}$ Among the attrited, 74\% had died before 1996.
} 
malaria infection than those who had died. This bias would lead to an underestimate of the malaria exposure effect on health in later life. While we cannot directly address this issue, we can still view our estimates as a lower-bound estimate of the malaria exposure effect.

Cognitive functions and cardiovascular diseases

We use two measures of cognitive functions: words recalled and backward counting. ${ }^{26}$ In panel A of Table 6, the dependent variable is total words correctly recalled (mean is 3.9 words out of 10 words). In Panel B, the dependent variable is a dummy variable indicating success in backward counting (mean is .19 ). ${ }^{27}$ Overall, OLS estimates reported in Panel A and B of Table 6 show that lower exposure to the risk of contracting malaria leads to better cognitive functions at old age. Specifically, one less malaria death per 1,000 people would lead to .16 .35 more words recalled and 4 8 percentage points higher in probability of successful backward counting.

The presence of cardiovascular disease is represented by two dummy variables that respectively indicate whether an individual had self-reported high blood pressure (mean is .29) or a self-reported heart problem (mean is .17). OLS estimates in Panel C and $\mathrm{D}$ suggest that one less malaria death per 1,000 is associated with a lower probability of having either of these two conditions by about 3 percentage points. Results are generally statistically significant.

Table 7 summarizes the 2SLS results on the health outcomes, and the results mirror those for the education outcomes, in that they are not only robust, but generally

\footnotetext{
${ }^{26}$ For words recall test, the elders were read 10 words and asked to recall them immediately. For backward counting, the elders were read a sequence of 5 single-digit numbers and asked to immediately count the sequence backward.

${ }^{27}$ There were about 380 elders who were interviewed using proxy. The two outcomes (words recalled and backward counting) are thus not available for these elders.
} 
larger in magnitude than the OLS estimates. ${ }^{28}$ The estimated coefficient of the malaria variables for words recalled and backward counting are generally 2 4 times larger than the OLS estimates (Panel A and B). The results on high blood pressure are also 1.5 3 times larger than OLS (Panel C). The exception is the estimation results on the presence of self-reported heart problems; they are similar in magnitude to the OLS estimates but not statistically significant (Panel D).

\section{Mortality}

Survival can be viewed as a robust reflection of health status, and the impact of exposure to malaria on the risk of mortality has obvious implications for public health policy. Quite apart from the moral issues of evaluating life there are important quantifiable benefits of prolonging productive working life and obtaining a longer payout to educational expenditures. Thus, we study whether early life exposure to malaria accelerates the timing of death.

An advantage of our data is that we have information about month and year of death for all individuals in our sample up to the end of 2007. We adopt a Cox proportional hazard model to estimate the effect of malaria exposure on the risk of mortality. To address the possible problem of unobserved heterogeneity, we use a control function approach by using residuals obtained from a first stage regression of malaria death rates on exogenous variables when estimating the Cox model. ${ }^{29}$

The estimation results for the hazard model are reported in Table 8. Panel A reports the original estimates of coefficients, while Panel B reports the corresponding hazard ratios based on the coefficient estimates. Column (1) and (5) are results obtained

\footnotetext{
${ }^{28}$ Specifications are the same to column (3) and (6) in Table 6.

${ }^{29}$ The exogenous variables include the right-hand-side variables in equation (1) except for Malaria.
} 
without addressing the unobserved heterogeneity issue, while the other columns are results obtained from the control function approach.

We focus on the hazard ratios in Panel B. Column (1) and (5) suggest that one less malaria death per 1,000 people would lower the mortality hazard by between $12 \%$ and $18 \%$. After correcting for the measurement errors, the control function estimates are generally 1.5 to 2.6 times the magnitude of those in column (1) and (5). This increase in magnitude after correcting for measurement errors is similar to that which occurs with IV estimation of other outcomes compared to their OLS counterparts. All results are statistically significant. Our results on mortality show that malaria exposure risk is not only negatively associated with human capital accumulation but also reduces the life span and that in fact the effect is sizeable. This is new information along with other health outcomes at old ages that should be considered when evaluating cost-benefit analysis of malaria eradication policies in developing countries.

\subsection{The Effects of Malaria Exposure at Different Ages}

In theory, children, especially those under age 5 who have not yet developed protective immunity, are all susceptible to malaria infection. To examine how malaria exposures at different ages affect later outcomes, we separately re-estimate equation (3) using malaria death rate in different years relative to birth year. In particular, the window ranges from one year before birth to five years after birth. We exclude those who were born during 1937-1941 because malaria death rates after 1941 are not available. 
Figure 6 plots the effects of malaria exposure at different years relative to birth. ${ }^{30}$ In general, the effects are highest in the birth year and the year before birth across all outcomes, then decreasing sharply after birth, but reversing trend in year four and five for some outcomes. Even with this reversal, the effects for years four and five are generally smaller than those in the year before birth and the birth year. This suggests that it is in the year before birth and the birth year that exposure to malaria implies the most serious long-term health outcomes.

\section{Conclusions}

We add to the literature on the impact of early-life health shocks to the development of individual human capital by estimating the long-term impact of malaria exposure risk around birth on educational attainment and health outcomes in later life. Our findings imply that exposure to malaria in utero or during early infancy on average leads to lower life-time educational attainment as well as to worse health outcomes in later life. Our findings add to the body of results from epidemiological studies corroborating support of the fetal-origins hypothesis.

Our findings on health outcomes contribute to the literature evaluating the benefits of malaria eradication. Bleakley (2010) points out that malaria eradication can increase both the benefit and the opportunity cost of investment in education, implying an ambiguous effect of malaria morbidity on education outcomes. As we argue in the body of this paper, health outcomes are likely less ambiguous measures than education outcomes of the benefits of malaria eradication.

\footnotetext{
${ }^{30}$ For readers' convenience, we reverse the signs of the estimates of education outcomes and cognitive functions, whose original signs are negative, so that a larger positive number means a larger effect for all outcomes.
} 
We consider our estimates to represent a lower bound on the true impact of the effects of malaria exposure. Our 2SLS results are generally much larger than the OLS results. We attribute this increase in magnitude to classical measurement-error bias due to the use of the malaria death rate as a measure of malaria exposure risk and to the impact of survivor bias because those who lived long enough to be counted in our samples, despite being exposed to and possibly contracting malaria, were presumably stronger in other respects than the general population.

Our estimation results imply that early life exposure to malaria could influence outcomes over the entire life-cycle from education in youth to health in old age. Therefore, a comprehensive cost-benefit analysis of malaria eradication policies in developing countries should consider the policy effect in every stage in life. In addition, given the fact that malaria can affect outcomes in different stages in life, which further affect each other, it is worth devoting more future research efforts into disentangling the pathways for malaria to affect different outcomes in different stages and their interactions. 


\section{References}

Almond, D. (2006). "Is the 1918 Influenza pandemic over? Long-term effects of in utero influenza exposure in the post-1940 U.S. population.” The Journal of Political Economy, 114: 672-7122.

Almond, D., L. Edlund, H. Li and J. Zhang (2007). “long-term effects of the 1959-1961 China famine: mainland China and Hong Kong.” NBER working paper 13384.

Almond, D., and B. Mazumder (2005). “The 1918 influenza pandemic and subsequent health outcomes: an analysis of SIPP data.” The American Economic Review: Papers and Proceedings, 95 (2): 258-262.

Barker, D. (1992). “The fetal origins of diseases of old age.” European Journal of Clinical Nutrition, 46 (s): 3-9.

Barker, D. (1993). “The intrauterine origins of cardiovascular disease.” Acta Paediatrica 391: 93-99.

Barker, D. (1994). Mothers, babies and disease in later life. London: BMJ.

Barker, D. (1995). “Fetal origins of coronary heart disease.” British Medicine Journal, 311: 171-174.

Barreca, A. (2010). “The long-term economic impact of in utero and postnatal exposure to malaria.” Journal of Human Resources, 45(4): 865-892.

Bleakley, H. (2010). "Malaria eradication in the Americas: a retrospective analysis of childhood exposure.” American Economic Journal: Applied Economics, 2: 145.

Case, A., and C. Paxson (2009). "Early life health and cognitive function in old age.” The American Economic Review: Papers and Proceedings, 99 (2): 104-109.

Case, A., and C. Paxson (2010). “The long reach of childhood health and circumstatnce: evidence from the Whitehall II Study.” NBER working paper 15640.

Chen, Y., and L. Zhou (2007). “The long-term health and economic consequences of the 1959-1961 famine in China.” Journal of Health Economics, 26 (4): 659-681.

Cutler, D., W. Fung, M. Kremer, M. Singhal and T. Vogl. (2010). “Early-life malaria exposure and adult outcomes: evidence from malaria eradication in India.” American Economic Journal: Applied Economics, 2: 72-94. 
Department of Health, the Executive Yuan, Republic of China. (1991). Malaria eradication in Taiwan. Taipei, Taiwan.

Holding, P., and R. Snow (2001). "Impact of plasmodium falciparum malaria on performance and learning: review of the evidence.” American Journal of Tropical Medicine and Hygiene, 64: 68-75.

Kim, S., Q. Deng, F. Belton and S. Li (2010). “The lasting impact of mother's fetal malnutrition on their offspring: evidence from the China Great Leap Forward famine.”

Ku, Y. (2009). “Anti-malaria policy and its consequences in colonial Taiwan.” In Disease, Colonialism, and the State, edited by K. Yip. Hong Kong: Hong Kong University Press.

Liu, S. (2009). “The theory and practice of malariology in colonial Taiwan.” In Disease, Colonialism, and the State, edited by K. Yip. Hong Kong: Hong Kong University Press.

Lo, M. (2002). Doctors within borders. London: University of California Press.

Lucas, A. (2010). "Malaria eradication and educational attainment: evidence from Paraguay and Sri Lanca.” American Economic Journal: Applied Economics, 2: 46-71.

Meng, X., and N. Qian (2009). “The long term consequences of famine on survivors: evidence from a unique natural experiment using China's great famine.” NBER Working paper 14917.

Manendez, C., and A. Mayor (2007). “Congenital malaria: the least known consequence of malaria in pregnancy.” Seminars in Fetal and Neonatal Medicine, 12: 207-213.

Morishita, K., (1976). The epidemiology and prevention of Malaria, Tokyo: Kikuya. (In Japanese)

Poespoprodjo, J., et al. (2010). “Case report: severe congenital malaria acquired in utero.” American Journal of Tropical Medicine and Hygiene, 82 (4): 563-565.

Rasmussen, K. (2001). “The "fetal origins” hypothesis: challenges and opportunities for maternal and child nutrition.” Annual Review of Nutrition, 21:73-95.

Sawa, K., (1931). "Experimental study on malaria plasmodium in Taiwanese anopheles.” Journal of Taiwan Medical Association, 30 (315): 609-632. (In Japanese) 
Tetsuzou, S., (2007). “The opening of sanitary policies in early Japanese Taiwan-from the public health physician reports.” Journal of Taiwan Normal University, 37: 143-180. (In Chinese)

Ting, K. (2008). “The public hygiene of the area of Yunlin County during the Japanese ruling period of Taiwan.” Journal of Living Sciences, 11: 195-243. (In Chinese)

Yearly Statistics Books of the Office of the Governor-General in Taiwan from 1895 to1945. Online archive: http://tcsd.lib.ntu.edu.tw/main_browse.php.

WHO (2010). Health Topics on Malaria http://www.who.int/topics/malaria/en/. 


\section{Appendix 1: Historical Data}

\section{Administrative Division Changes}

During 1901-1941, administrative divisions were redrawn in 1909 and 1920. Before 1920, divisions were called Ting; after 1920, some were called Zhou (prefecture) and others were still called Ting. In general, a Zhou is about the size of 3-4 Tings. During 1901-1908, there were 19 Tings on the main island of Taiwan. ${ }^{31}$ During 1909-1919, there were 11 Tings. After 1920, there were five Zhous in the west and two Tings in the east. In this paper, we use the division after 1920 as basis. We group two Zhous in the south and two Tings in the east to minimize the inconsistency caused by the division changes. Therefore, we have 5 divisions in the end. For convenience, we call them prefecture. There are still three townships belonging to different prefectures according to our definition in different periods. For individuals born to these three townships, we include three dummy variables into all regressions to pick up the effect caused by the administrative division inconsistency.

\section{Malaria Death Rate}

We count the yearly malaria deaths for the 5 prefectures and then divide them by corresponding population (in thousands). Note that the malaria deaths and population include both Taiwanese and Japanese. The Japanese accounts for less than 5\% of the population in the colonial period.

\section{Public Health Physicians}

We have information of public health physicians in each administrative division in the colonial period except for 1920-1924. For 1920-1924, we only know the total

\footnotetext{
${ }^{31}$ The jurisdiction of the colonial Taiwan also includes an archipelago called Pescadores, which is off the southwestern coast.
} 
number for whole Taiwan. The total number shows a smooth growing trend. We thus impute the time trend in each division for these years.

\section{Agricultural Production}

Taiwan was an agrarian economy during the colonial period. The two most important agricultural products then were rice and sugar cane. While sugar cane was most popular in the south, rice was widespread in the whole island. We thus calculate the per capita value of rice and sugar cane production in each prefecture to measure the local economic status. We use the prices of rice and sugar cane in 1929. This variable is included in all regressions as a control for time-varying local economic status. Primary Schools

To control for local education resources, we use the number of primary schools per 100,000 people and this variable is also included in every regression. Primary schools were the most available education resource to native Taiwanese in the colonial period. For more details on education in colonial Taiwan, see Appendix 2 in the next section. 


\section{Appendix 2: Education in Colonial Taiwan}

The colonial government implemented a segregation policy in education until 1941. Japanese children and Taiwanese children went to different schools (Tsurumi 1979). Schools for the Japanese children generally were of better quality and resources (Tsurumi 1977). Primary schools for Taiwanese children were called common schools. Common schools offered modern courses such as arithmetic, basic sciences, Japanese, etc. Throughout the colonial period, common schools increased only gradually (Zimmer, Liu, Hermalin and Chuang 1998).

Post-primary education was very limited for the Taiwanese (Tsurumi, 1979). A few vocational schools, including normal schools, were founded after 1919, and one university was finally established in 1928, mainly to accommodate the Japanese youth on the island. Only one medical school existed throughout the entire colonial period. The few Taiwanese who obtained post-primary education generally received training in medicine or teaching.

\section{Reference}

Tsurumi, E. (1979). "Education and assimilation in Taiwan under the Japanese rule, 1895-1945.” Modern Asian Studies, 13 (4): 617-641.

Zimmer, Z., X. Liu, A. Hermalin, and Y. Chuang. (1998). "Educational attainment and transitions in functional status among older Taiwanese.” Demography, 35(3): 361-375. 


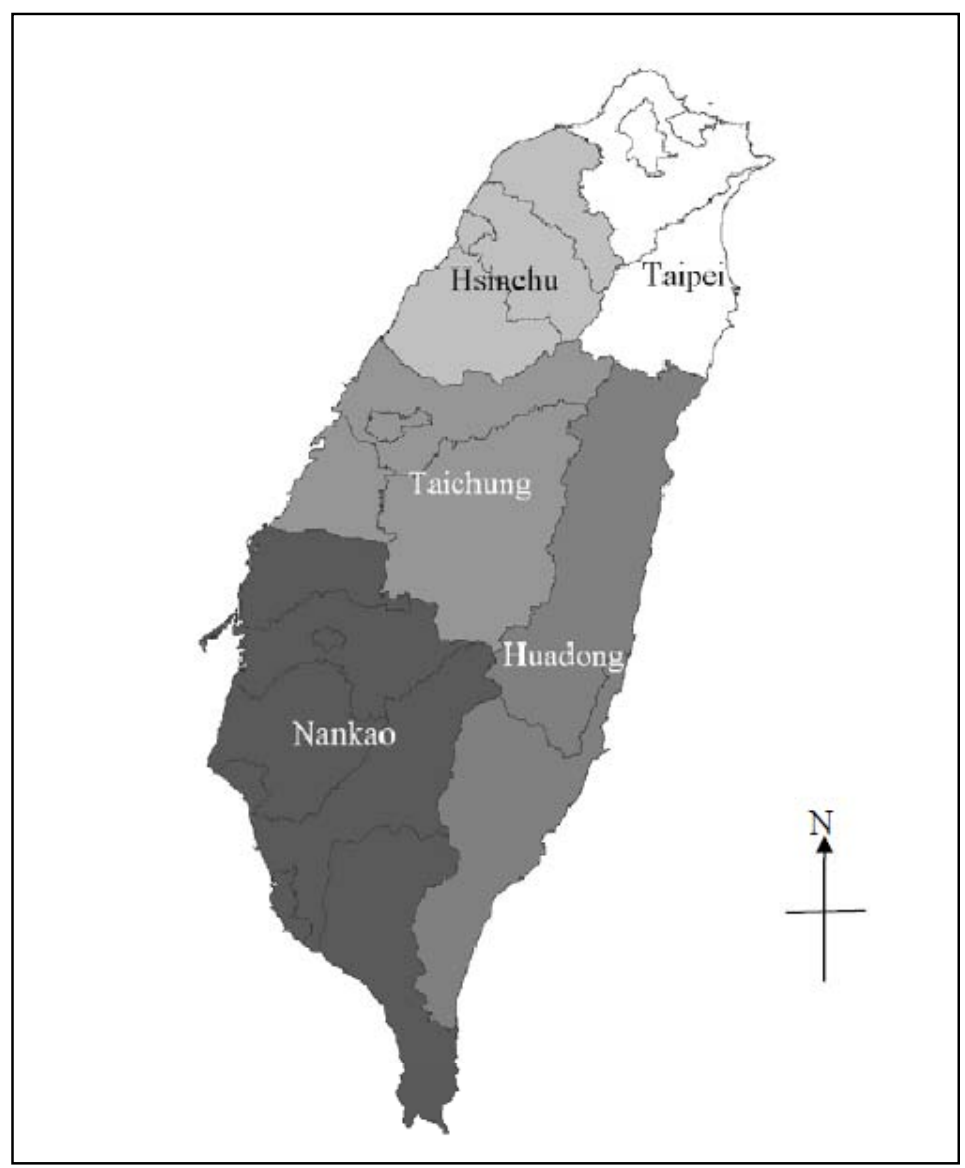

Figure 1. Prefectures and malaria severity in 1920 

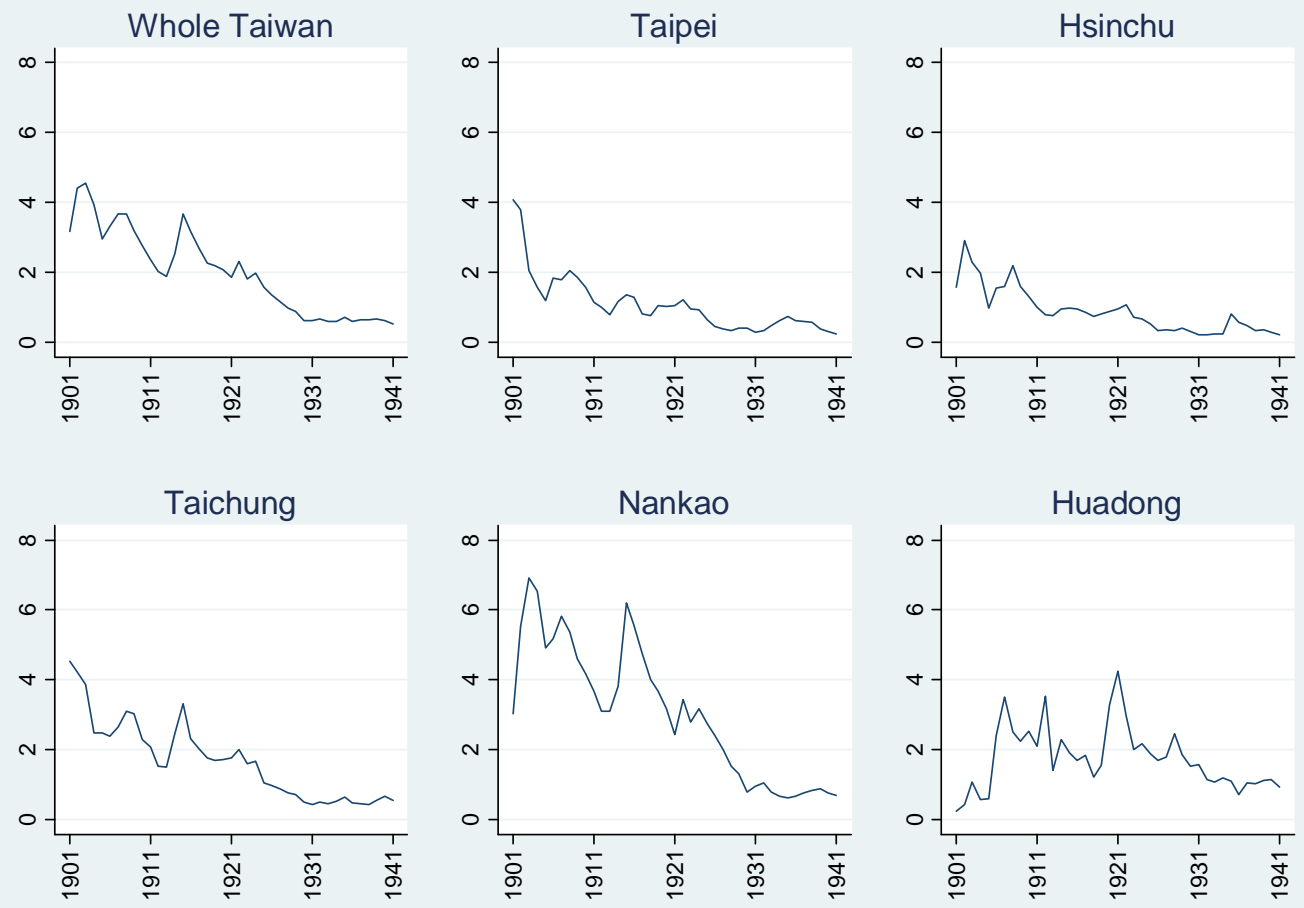

Figure 2. Malaria deaths per 1,000 in colonial Taiwan 

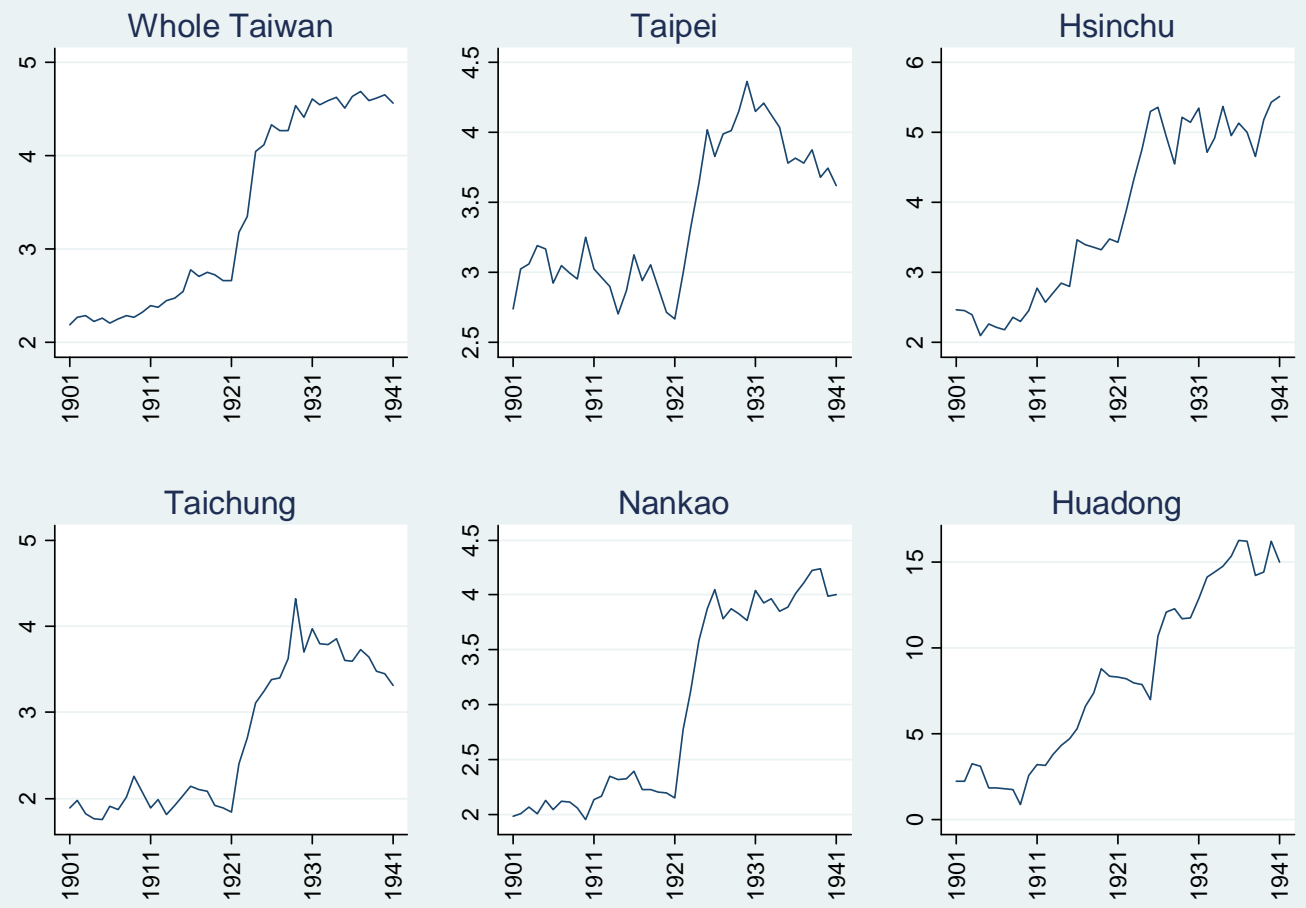

Figure 3. Number of public health physicians per 100,000 

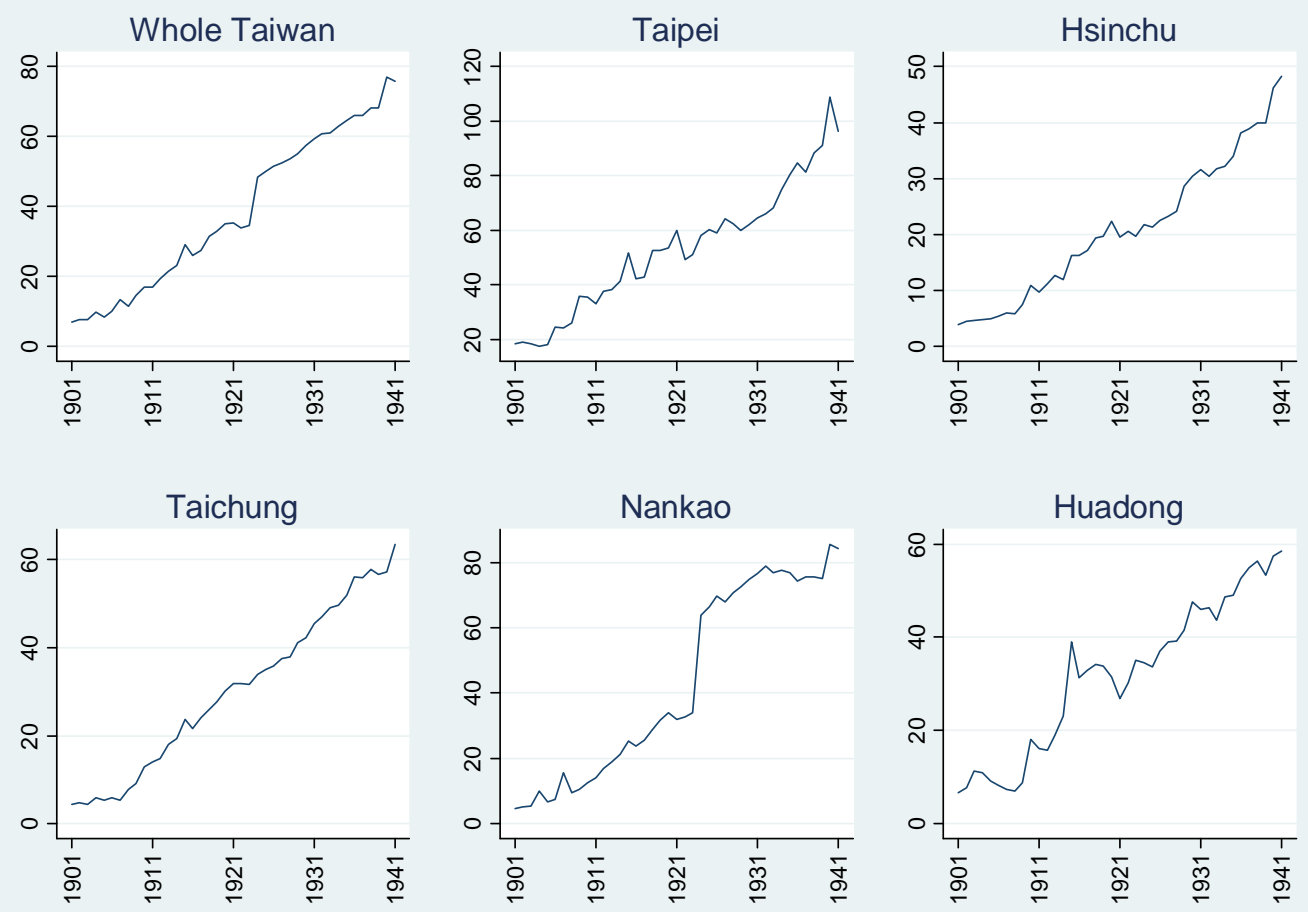

Figure 4. Number of other medical personnel per 100,000 

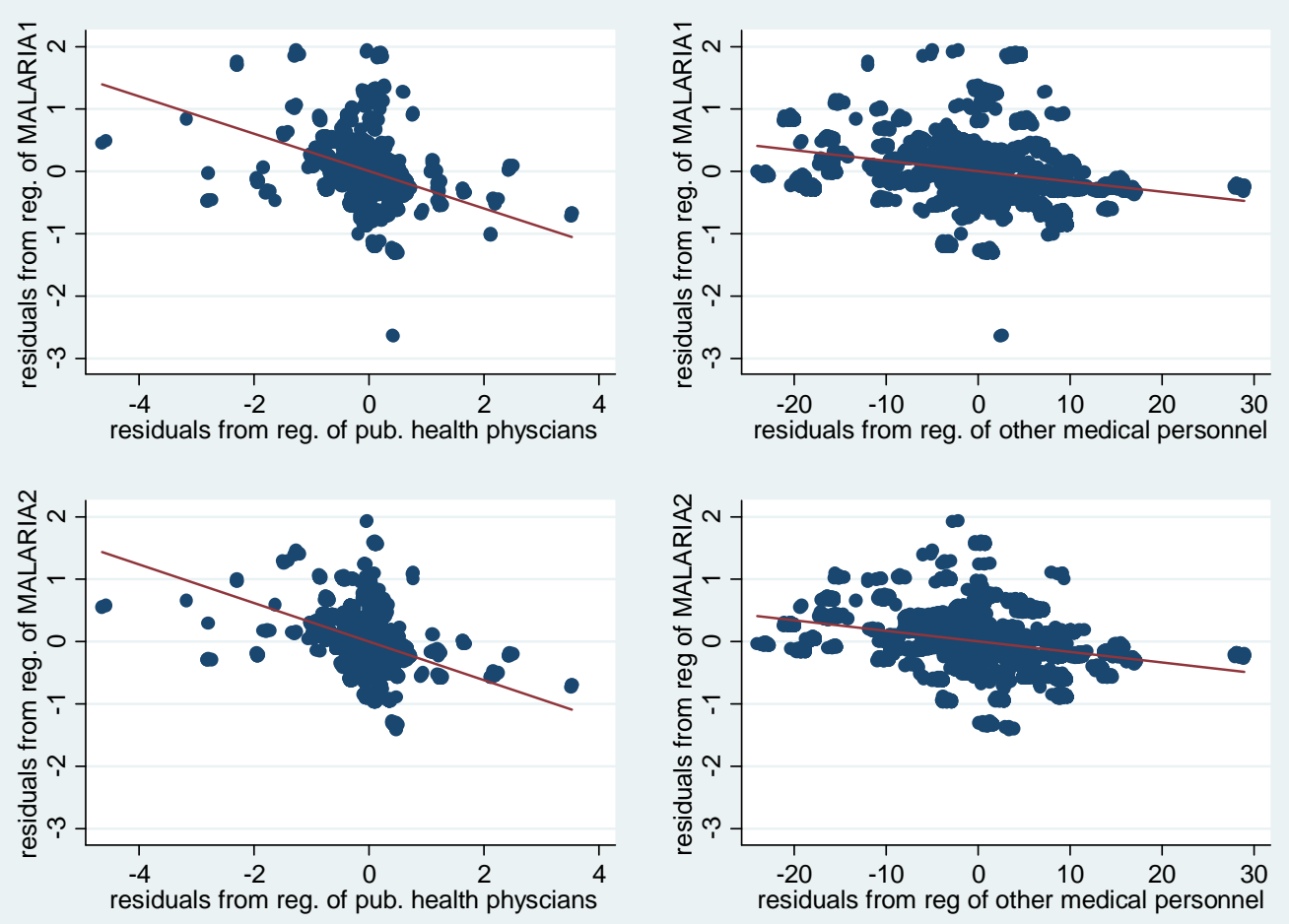

Figure 5. Partial correlation of malaria death rates with IVs 

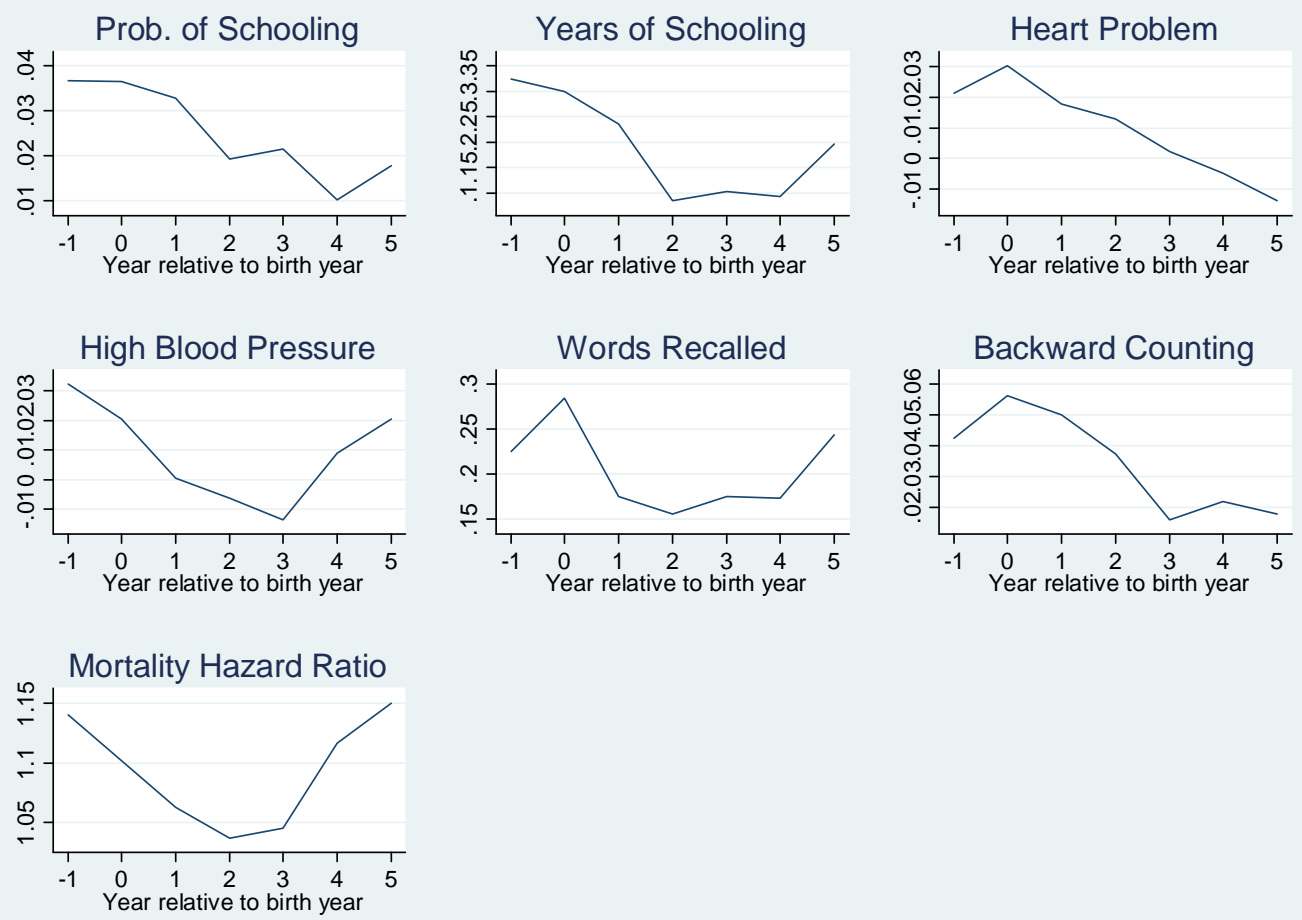

Figure 6. Effects of malaria exposure in different years relative to birth year 


\section{Table 1. OLS estimates of malaria exposure effect on education}

\begin{tabular}{|c|c|c|c|c|c|c|}
\hline & $(1)$ & $(2)$ & (3) & $(4)$ & $(5)$ & $(6)$ \\
\hline & \multicolumn{6}{|c|}{ Panel A: have any schooling=1 if yes [mean $=0.51]$} \\
\hline MALARIA1 & $\begin{array}{c}-0.028^{* *} \\
(0.014)\end{array}$ & $\begin{array}{c}-0.055^{* *} \\
(0.021)\end{array}$ & $\begin{array}{c}-0.045^{* * *} \\
(0.017)\end{array}$ & & & \\
\hline MALARIA2 & & & & $\begin{array}{c}-0.031^{* *} \\
(0.013)\end{array}$ & $\begin{array}{c}-0.063 * * * \\
(0.019)\end{array}$ & $\begin{array}{c}-0.051 * * * \\
(0.017)\end{array}$ \\
\hline observations & 4,575 & 4,575 & 4,575 & 4,566 & 4,566 & 4,566 \\
\hline \multirow[t]{2}{*}{$\mathrm{R}^{2}$} & 0.08 & 0.08 & 0.32 & 0.08 & 0.08 & 0.32 \\
\hline & \multicolumn{6}{|c|}{ Panel B: years of schooling [mean=3.39] } \\
\hline MALARIA1 & $\begin{array}{c}-0.113 \\
(0.097)\end{array}$ & $\begin{array}{c}-0.416^{* * *} \\
(0.151)\end{array}$ & $\begin{array}{c}-0.355^{* * *} \\
(0.124)\end{array}$ & & & \\
\hline MALARIA2 & & & & $\begin{array}{l}-0.130 \\
(0.094)\end{array}$ & $\begin{array}{c}-0.521^{* * *} \\
(0.132)\end{array}$ & $\begin{array}{c}-0.442 * * * \\
(0.133)\end{array}$ \\
\hline observations & 4,575 & 4,575 & 4,575 & 4,566 & 4,566 & 4,566 \\
\hline $\mathrm{R}^{2}$ & 0.06 & 0.07 & 0.38 & 0.06 & 0.07 & 0.38 \\
\hline grouped birth-cohort dummies & Yes & Yes & Yes & Yes & Yes & Yes \\
\hline prefecture dummies & Yes & Yes & Yes & Yes & Yes & Yes \\
\hline interaction of the two dummies & & Yes & Yes & & Yes & Yes \\
\hline other controls & & & Yes & & & Yes \\
\hline $\begin{array}{l}\text { Notes: robust standard errors clustered } \\
\text { career occupation, numbers of primary } \\
\text { prefecture; all regressions include } 3 \text { du } \\
\text { divisions; } *, * *, * * * \text { means significant }\end{array}$ & $\begin{array}{l}\text { prefecture ar } \\
100,000 \text { and } \mathrm{F} \\
\text { 1dicate region }\end{array}$ & $\begin{array}{l}\text { parentheses; } \\
\text { luction of suy } \\
\text { elonging to }\end{array}$ & $\begin{array}{l}\text { her controls in } \\
\text { cane and rice } \\
\text { erent counties }\end{array}$ & $\begin{array}{l}\text { de sex, ethni } \\
\text { r capita (mea } \\
\text { ross periods }\end{array}$ & $\begin{array}{l}\text { y, father's edu } \\
\text { red in } 1929 \text { pri } \\
\text { to changes in }\end{array}$ & $\begin{array}{l}\text { ion, father's } \\
\text { ) in birth year } \\
\text { ministration }\end{array}$ \\
\hline
\end{tabular}


Table 2. Robustness check for birth place and current residence using the cohort 1901-1929

\begin{tabular}{|c|c|c|c|c|c|c|}
\hline & $(1)$ & $(2)$ & $(3)$ & $(4)$ & $(5)$ & $(6)$ \\
\hline & \multicolumn{6}{|c|}{ Panel A: have any schooling=1 if yes [mean=0.44] } \\
\hline \multicolumn{7}{|l|}{ MALARIA1 defined by } \\
\hline birth prefecture & $\begin{array}{c}-0.041 * * \\
(0.020)\end{array}$ & $\begin{array}{c}-0.053 * * \\
(0.022)\end{array}$ & $\begin{array}{c}-0.036 * * \\
(0.016)\end{array}$ & & & \\
\hline residence prefecture & $\begin{array}{c}-0.037 * * \\
(0.019)\end{array}$ & $\begin{array}{c}-0.053 * * \\
(0.021)\end{array}$ & $\begin{array}{c}-0.039 * * \\
(0.016)\end{array}$ & & & \\
\hline \multicolumn{7}{|l|}{ MALARIA2 defined by } \\
\hline birth prefecture & & & & $\begin{array}{c}-0.047 * * \\
(0.019)\end{array}$ & $\begin{array}{c}-0.060^{* * *} \\
(0.020)\end{array}$ & $\begin{array}{c}-0.041^{* *} \\
(0.016)\end{array}$ \\
\hline \multirow[t]{2}{*}{ residence prefecture } & & & & $\begin{array}{c}-0.044^{* *} \\
(0.018)\end{array}$ & $\begin{array}{c}-0.064^{* * *} \\
(0.020)\end{array}$ & $\begin{array}{c}-0.047 * * * \\
(0.018)\end{array}$ \\
\hline & \multicolumn{6}{|c|}{ Panel B: years of schooling [mean=2.91] } \\
\hline MALARIA1 defined by & & & & & & \\
\hline birth prefecture & $\begin{array}{l}-0.25^{*} \\
(0.139)\end{array}$ & $\begin{array}{c}-0.392 * * \\
(0.154)\end{array}$ & $\begin{array}{c}-0.264^{* *} \\
(0.118)\end{array}$ & & & \\
\hline residence prefecture & $\begin{array}{l}-0.242 * \\
(0.125)\end{array}$ & $\begin{array}{c}-0.405^{* * *} \\
(0.137)\end{array}$ & $\begin{array}{c}-0.288 * * \\
(0.113)\end{array}$ & & & \\
\hline \multicolumn{7}{|l|}{ MALARIA2 defined by } \\
\hline birth prefecture & & & & $\begin{array}{c}-0.328 * * \\
(0.131)\end{array}$ & $\begin{array}{c}-0.507 * * * \\
(0.139)\end{array}$ & $\begin{array}{c}-0.363^{* *} \\
(0.125)\end{array}$ \\
\hline residence prefecture & & & & $\begin{array}{c}-0.304^{* *} \\
(0.125)\end{array}$ & $\begin{array}{c}-0.521^{* * *} \\
(0.140)\end{array}$ & $\begin{array}{c}-0.378 * * * \\
(0.132)\end{array}$ \\
\hline observations & 3,022 & 3,022 & 3,022 & 3,013 & 3,013 & 3,013 \\
\hline grouped birth-cohort dummies & Yes & Yes & Yes & Yes & Yes & Yes \\
\hline prefecture dummies & Yes & Yes & Yes & Yes & Yes & Yes \\
\hline interaction of the two dummies & & Yes & Yes & & Yes & Yes \\
\hline other controls & & & Yes & & & Yes \\
\hline
\end{tabular}




\section{Table 3. First-stage regressions of malaria death rates on instrumental variables}

\begin{tabular}{|c|c|c|c|}
\hline & $(1)$ & $(2)$ & (3) \\
\hline Instrumental variables: & \multicolumn{3}{|c|}{ Panel A: MALARIA1 } \\
\hline Public health physicians & \multirow[t]{2}{*}{$\begin{array}{c}-0.300 * * * \\
(0.059)\end{array}$} & & $\begin{array}{c}-0.234 * * * \\
(0.055)\end{array}$ \\
\hline Other medical personnel & & $\begin{array}{c}-0.017 * * * \\
(0.005)\end{array}$ & $\begin{array}{c}-0.012^{* *} \\
(0.005)\end{array}$ \\
\hline \multirow[t]{2}{*}{ observations } & $\begin{array}{l}10.99 \\
4,575\end{array}$ & $\begin{array}{c}9.92 \\
4,575\end{array}$ & $\begin{array}{l}12.53 \\
4,575\end{array}$ \\
\hline & \multicolumn{3}{|c|}{ Panel B: MALARIA2 } \\
\hline Public health physicians & $\begin{array}{c}-0.310^{* * *} \\
(0.052)\end{array}$ & & $\begin{array}{c}-0.244^{* * * *} \\
(0.053)\end{array}$ \\
\hline Other medical personnel & & $\begin{array}{c}-0.017 * * * \\
(0.004)\end{array}$ & $\begin{array}{c}-0.012 * * * \\
(0.004)\end{array}$ \\
\hline Partial F & 36.06 & 17.47 & 19.39 \\
\hline observations & 4,566 & 4,566 & 4,566 \\
\hline \multicolumn{4}{|c|}{$\begin{array}{l}\text { Notes: all regressions include full sets of cohort dummies, county dummies and the interaction terms of the } \\
\text { two, and other controls; partial F statistics test the join significance of the instrument variables; robust } \\
\text { standard errors clustered at birth year/ prefecture are in parentheses; *, **, } * * * \text { means significant at } 10 \% \text {, } \\
5 \% \text { and } 1 \% \text {; see Table } 1 \text { for notes of control variables. }\end{array}$} \\
\hline
\end{tabular}


Table 4. 2SLS estimates of malaria exposure effect on education

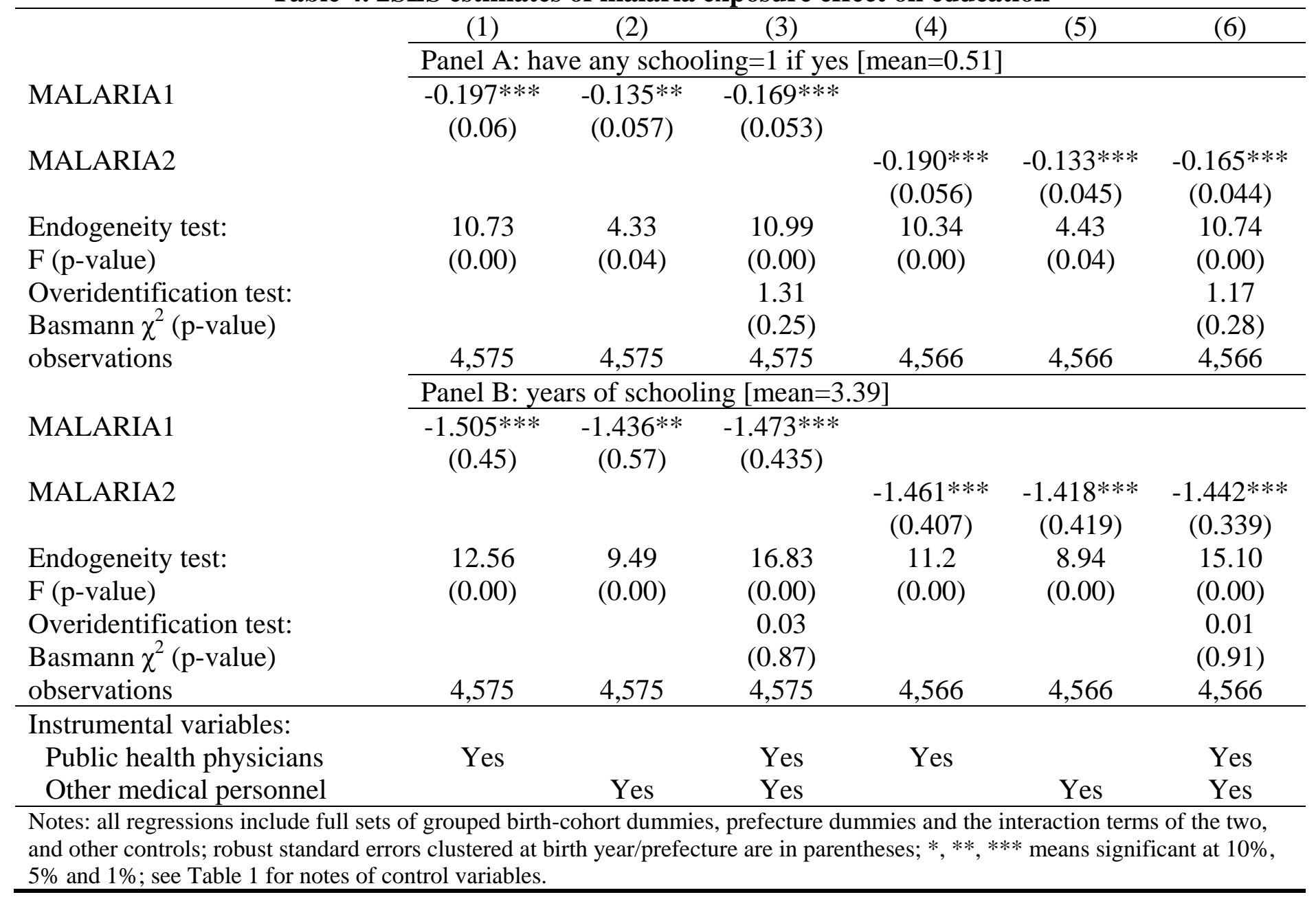


Table 5. OLS and 2SLS estimates on probability of having any schooling using 1980 census data

\begin{tabular}{|c|c|c|c|c|c|c|}
\hline & $(1)$ & $(2)$ & (3) & (4) & $(5)$ & $(6)$ \\
\hline & \multicolumn{6}{|c|}{ Panel A: OLS estimates } \\
\hline MALARIA1 & $\begin{array}{c}-0.033 * * * \\
(0.006)\end{array}$ & $\begin{array}{c}-0.047 * * * \\
(0.011)\end{array}$ & $\begin{array}{c}-0.043 * * * \\
(0.009)\end{array}$ & & & \\
\hline MALARIA2 & & & & $\begin{array}{c}-0.036 * * * \\
(0.007)\end{array}$ & $\begin{array}{c}-0.059 * * * \\
(0.013)\end{array}$ & $\begin{array}{c}-0.054 * * * \\
(0.010)\end{array}$ \\
\hline $\mathrm{R}^{2}$ & 0.13 & 0.13 & 0.23 & 0.12 & 0.12 & 0.23 \\
\hline grouped birth-cohort dummies & Yes & Yes & Yes & Yes & Yes & Yes \\
\hline prefecture dummies & Yes & Yes & Yes & Yes & Yes & Yes \\
\hline interaction of the two dummies & & Yes & Yes & & Yes & Yes \\
\hline \multirow[t]{2}{*}{ other controls } & & & Yes & & & Yes \\
\hline & \multicolumn{6}{|c|}{ Panel B: 2SLS estimates } \\
\hline MALARIA1 & $\begin{array}{c}-0.171 * * * \\
(0.027)\end{array}$ & $\begin{array}{c}-0.257 * * * \\
(0.075)\end{array}$ & $\begin{array}{c}-0.202 * * * \\
(0.035)\end{array}$ & & & \\
\hline MALARIA2 & & & & $\begin{array}{c}-0.163 * * * \\
(0.021)\end{array}$ & $\begin{array}{c}-0.255^{* * *} \\
(0.06)\end{array}$ & $\begin{array}{c}-0.195^{* * *} \\
(0.025)\end{array}$ \\
\hline Instrumental variables: & & & & & & \\
\hline Public health physicians & Yes & & Yes & Yes & & Yes \\
\hline Other medical personnel & & Yes & Yes & & Yes & Yes \\
\hline observations & $4,436,007$ & $4,436,007$ & $4,436,007$ & $4,420,856$ & $4,420,856$ & $4,420,856$ \\
\hline
\end{tabular}




\begin{tabular}{|c|c|c|c|c|c|c|}
\hline \multicolumn{7}{|c|}{ Table 6. OLS estimates of malaria exposure effect on cognitive functions and cardiovascular diseases at old age } \\
\hline & $(1)$ & $(2)$ & $(3)$ & $(4)$ & $(5)$ & (6) \\
\hline \multirow[b]{2}{*}{ MALARIA1 } & \multicolumn{6}{|c|}{ Panel A: words recalled (max=10 words) [mean=3.9] } \\
\hline & $\begin{array}{c}-0.158 * * * \\
(0.059)\end{array}$ & $\begin{array}{c}-0.228 * * \\
(0.090)\end{array}$ & $\begin{array}{c}-0.309 * * * \\
(0.094)\end{array}$ & \multirow[b]{2}{*}{$\begin{array}{c}-0.170^{* * *} \\
(0.062)\end{array}$} & \multirow[b]{2}{*}{$\begin{array}{c}-0.266^{* *} \\
(0.107)\end{array}$} & \multirow[b]{2}{*}{$\begin{array}{c}-0 . .345^{* * *} \\
(0.111)\end{array}$} \\
\hline MALARIA2 & & & & & & \\
\hline observations & 3,294 & 3,294 & 3,294 & 3,293 & 3,293 & 3,293 \\
\hline \multirow[t]{2}{*}{$\mathrm{R}^{2}$} & 0.07 & 0.07 & 0.11 & 0.06 & 0.07 & 0.11 \\
\hline & \multicolumn{6}{|c|}{ Panel B: backward counting=1 if correct [mean=0.19] } \\
\hline MALARIA1 & $\begin{array}{c}-0.038 * * * \\
(0.010)\end{array}$ & $\begin{array}{c}-0.060 * * * \\
(0.012)\end{array}$ & \multirow[t]{2}{*}{$\begin{array}{c}-0.068 * * * \\
(0.014)\end{array}$} & & & \\
\hline MALARIA2 & & & & $\begin{array}{c}-0.040^{* * *} \\
(0.011)\end{array}$ & $\begin{array}{c}-0.068 * * * \\
(0.014)\end{array}$ & $\begin{array}{c}-0.075^{* * *} \\
(0.016)\end{array}$ \\
\hline observations & 3,294 & 3,294 & 3,294 & 3,293 & 3,293 & 3,293 \\
\hline \multirow[t]{2}{*}{$\mathrm{R}^{2}$} & 0.04 & 0.04 & 0.09 & 0.04 & 0.04 & 0.09 \\
\hline & \multicolumn{6}{|c|}{ Panel C: high blood pressure=1 if reported yes [mean=0.29] } \\
\hline MALARIA1 & $\begin{array}{c}0.026 * * \\
(0.011)\end{array}$ & $\begin{array}{c}0.012 \\
(0.017)\end{array}$ & \multirow[t]{2}{*}{$\begin{array}{l}0.039 * \\
(0.020)\end{array}$} & & & \\
\hline MALARIA2 & & & & $\begin{array}{c}0.033 * * * \\
(0.012)\end{array}$ & $\begin{array}{c}0.024 \\
(0.019)\end{array}$ & $\begin{array}{l}0.039 * \\
(0.020)\end{array}$ \\
\hline observations & 3,577 & 3,577 & 3,577 & 3,572 & 3,572 & 3,572 \\
\hline \multirow[t]{2}{*}{$\mathrm{R}^{2}$} & 0.01 & 0.01 & 0.03 & 0.01 & 0.01 & 0.01 \\
\hline & \multicolumn{6}{|c|}{ Panel D: heart problem=1 if reported yes [mean=0.17] } \\
\hline MALARIA1 & $\begin{array}{c}0.030 * * * \\
(0.009)\end{array}$ & $\begin{array}{c}0.026 * * \\
(0.012)\end{array}$ & $\begin{array}{c}0.032 * * \\
(0.012)\end{array}$ & & & \\
\hline MALARIA2 & & & & $\begin{array}{c}0.031 * * * \\
(0.010)\end{array}$ & $\begin{array}{c}0.030 * * \\
(0.015)\end{array}$ & $\begin{array}{c}0.035^{* *} \\
(0.016)\end{array}$ \\
\hline observations & 3,577 & 3,577 & 3,577 & 3,572 & 3,572 & 3,572 \\
\hline
\end{tabular}


$\mathrm{R}^{2}$

grouped birth-cohort dummies

prefecture dummies

interaction of the two dummies

other controls

Notes: only elders

\begin{tabular}{cccccc}
0.02 & 0.02 & 0.03 & 0.02 & 0.02 & 0.03 \\
\hline Yes & Yes & Yes & Yes & Yes & Yes \\
Yes & Yes & Yes & Yes & Yes & Yes \\
& Yes & Yes & & Yes & Yes \\
& & Yes & & & Yes \\
& & &
\end{tabular}




\begin{tabular}{|c|c|c|c|c|c|c|}
\hline & $(1)$ & $(2)$ & $(3)$ & $(4)$ & $(5)$ & $(6)$ \\
\hline & \multicolumn{6}{|c|}{ Panel A: words recalled (max=10 words) [mean=3.9] } \\
\hline MALARIA1 & $\begin{array}{c}-1.048 * * * \\
(0.323)\end{array}$ & $\begin{array}{c}-1.011 * * * \\
(0.331)\end{array}$ & $\begin{array}{c}-1.031 * * * \\
(0.272)\end{array}$ & & & \\
\hline MALARIA2 & & & & $\begin{array}{c}-1.077^{* * *} \\
(0.332)\end{array}$ & $\begin{array}{c}-1.091^{* * *} \\
(0.372)\end{array}$ & $\begin{array}{c}-1.083 * * * \\
(0.283)\end{array}$ \\
\hline Endogeneity test: & 5.71 & 11.41 & 10.78 & 5.51 & 9.97 & 10.12 \\
\hline F (p-value) & $(0.02)$ & $(0.00)$ & $(0.00)$ & $(0.02)$ & $(0.00)$ & $(0.00)$ \\
\hline Overidentification test: & & & 0.01 & & & 0.00 \\
\hline Basmann $\chi^{2}$ (p-value) & & & $(0.92)$ & & & $(0.97)$ \\
\hline \multirow[t]{2}{*}{ observations } & 3,294 & 3,294 & 3,294 & 3,293 & 3,293 & 3,293 \\
\hline & \multicolumn{6}{|c|}{ Panel B: backward counting=1 if correct [mean=0.19] } \\
\hline MALARIA1 & $\begin{array}{c}-0.184 * * * \\
(0.043)\end{array}$ & $\begin{array}{c}-0.180 * * * \\
(0.058)\end{array}$ & $\begin{array}{c}-0.182 * * * \\
(0.041)\end{array}$ & & & \\
\hline MALARIA2 & & & & $\begin{array}{c}-0.189 * * * \\
(0.043)\end{array}$ & $\begin{array}{c}-0.194 * * * \\
(0.056)\end{array}$ & $\begin{array}{c}-0.191 * * * \\
(0.038)\end{array}$ \\
\hline Endogeneity test: & 8.49 & 8.57 & 14.26 & 7.87 & 7.93 & 13.02 \\
\hline F (p-value) & $(0.00)$ & $(0.00)$ & $(0.00)$ & $(0.01)$ & $(0.01)$ & $(0.00)$ \\
\hline Overidentification test: & & & 0.00 & & & 0.01 \\
\hline Basmann $\chi^{2}$ (p-value) & & & $(0.94)$ & & & $(0.93)$ \\
\hline \multirow[t]{2}{*}{ observations } & 3,294 & 3,294 & 3,294 & 3,293 & 3,293 & 3,293 \\
\hline & \multicolumn{6}{|c|}{ Panel C: high blood pressure $=1$ if reported yes [mean=0.29] } \\
\hline MALARIA1 & $\begin{array}{c}0.061 \\
(0.058)\end{array}$ & $\begin{array}{c}0.115^{* *} \\
(0.052)\end{array}$ & $\begin{array}{c}0.087 * * \\
(0.042)\end{array}$ & & & \\
\hline MALARIA2 & & & & $\begin{array}{c}0.061 \\
(0.058)\end{array}$ & $\begin{array}{c}0.121^{* *} \\
(0.056)\end{array}$ & $\begin{array}{c}0.087 * * \\
(0.044)\end{array}$ \\
\hline Endogeneity test: & 0.42 & 3.40 & 2.69 & 0.15 & 2.43 & 1.46 \\
\hline F (p-value) & $(0.52)$ & $(0.07)$ & $(0.10)$ & $(0.70)$ & $(0.12)$ & $(0.23)$ \\
\hline
\end{tabular}




\begin{tabular}{|c|c|c|c|c|c|c|}
\hline $\begin{array}{l}\text { Overidentification test: } \\
\text { Basmann } \chi^{2}(p-v a l u e) \\
\text { observations }\end{array}$ & 3,577 & 3,577 & $\begin{array}{l}0.68 \\
(0.41) \\
3,577\end{array}$ & 3,572 & 3,572 & $\begin{array}{l}0.79 \\
(0.38) \\
3,572\end{array}$ \\
\hline & \multicolumn{6}{|c|}{ Panel D: heart problem=1 if reported yes [mean=0.17] } \\
\hline MALARIA1 & $\begin{array}{c}0.041 \\
(0.039)\end{array}$ & $\begin{array}{c}0.036 \\
(0.032)\end{array}$ & $\begin{array}{c}0.039 \\
(0.053)\end{array}$ & & & \\
\hline MALARIA2 & & & & $\begin{array}{c}0.041 \\
(0.039)\end{array}$ & $\begin{array}{c}0.038 \\
(0.033)\end{array}$ & $\begin{array}{c}0.039 \\
(0.027)\end{array}$ \\
\hline Endogeneity test: & 0.06 & 0.02 & 0.09 & 0.02 & 0.01 & 0.03 \\
\hline F (p-value) & $(0.80)$ & $(0.88)$ & $(0.77)$ & $(0.88)$ & $(0.93)$ & $(0.87)$ \\
\hline Overidentification test: & & & 0.01 & & & 0.00 \\
\hline \multirow[t]{2}{*}{ Basmann $\chi^{2}$ (p-value) } & & & $(0.93)$ & & & $(0.96)$ \\
\hline & 3,577 & 3,577 & 3,577 & 3,572 & 3,572 & 3,572 \\
\hline \multicolumn{7}{|l|}{ Instrumental variables: } \\
\hline Public health physicians & Yes & & Yes & Yes & & Yes \\
\hline Other medical personnel & & Yes & Yes & & Yes & Yes \\
\hline \multicolumn{7}{|c|}{$\begin{array}{l}\text { Notes: only elders who were still alive in } 1996 \text { are included; all outcomes were measured in 1996; all regressions include full sets of } \\
\text { grouped birth-cohort dummies, prefecture dummies and the interaction terms of the two, and other controls; robust standard errors } \\
\text { clustered at birth year/prefecture are in parentheses; *, **, *** means significant at } 10 \%, 5 \% \text { and } 1 \% \text {; see Table } 1 \text { for notes of control } \\
\text { variables. }\end{array}$} \\
\hline
\end{tabular}


Table 8. Cox proportional hazard model estimates of malaria exposure effect on mortality

\begin{tabular}{|c|c|c|c|c|c|c|c|c|}
\hline & $(1)$ & $(2)$ & (3) & $(4)$ & $(5)$ & $(6)$ & $(7)$ & $(8)$ \\
\hline & \multicolumn{8}{|c|}{ Panel A: estimate of coefficient } \\
\hline MALARIA1 & $\begin{array}{c}0.116^{* * *} \\
(0.044)\end{array}$ & $\begin{array}{c}0.571 * * * \\
(0.153)\end{array}$ & $\begin{array}{c}1.095 * * * \\
(0.222)\end{array}$ & $\begin{array}{c}0.765 * * * \\
(0.147)\end{array}$ & & & & \\
\hline \multirow[t]{2}{*}{ MALARIA2 } & & & & & $\begin{array}{c}0.165 * * * \\
(0.048)\end{array}$ & $\begin{array}{c}0.544 * * * \\
(0.148)\end{array}$ & $\begin{array}{c}1.072 * * * \\
(0.216)\end{array}$ & $\begin{array}{c}0.738^{* * *} \\
(0.143)\end{array}$ \\
\hline & \multicolumn{8}{|c|}{ Panel B: hazard ratio } \\
\hline MALARIA1 & $\begin{array}{c}1.123 * * * \\
(0.049)\end{array}$ & $\begin{array}{c}1.770 * * * \\
(0.270)\end{array}$ & $\begin{array}{c}2.988 * * * \\
(0.663)\end{array}$ & $\begin{array}{c}2.149 * * * \\
(0.316)\end{array}$ & & & & \\
\hline MALARIA2 & & & & & $\begin{array}{c}1.180 * * * \\
(0.057)\end{array}$ & $\begin{array}{c}1.723^{* * *} \\
(0.256)\end{array}$ & $\begin{array}{c}2.923 * * * \\
(0.633)\end{array}$ & $\begin{array}{c}2.091 * * * \\
(0.300)\end{array}$ \\
\hline observations & 4,575 & 4,575 & 4,575 & 4,575 & 4,566 & 4,566 & 4,566 & 4,566 \\
\hline \multicolumn{9}{|l|}{ Instrumental variables: } \\
\hline Public health physicians & & Yes & & Yes & & Yes & & Yes \\
\hline Other medical personnel & & & Yes & Yes & & & Yes & Yes \\
\hline $\begin{array}{l}\text { Notes: for IV estimation in (2), } \\
\text { instrumental variables and all o } \\
\text { interaction terms of the two, an } \\
5 \% \text { and } 1 \% \text {; see Table } 1 \text { for not }\end{array}$ & $\begin{array}{l}\text { other controls; } \\
\text { s of control var }\end{array}$ & $\begin{array}{l}\text { bust standard } \\
\text { les. }\end{array}$ & $\begin{array}{l}\text { includes a v } \\
\text { hodels includ } \\
\text { ors clustered }\end{array}$ & $\begin{array}{l}\text { able of resid } \\
\text { ull sets of gr } \\
\text { birth year/pr }\end{array}$ & s from a first & $\begin{array}{l}\text { ge linear reg } \\
\text { ummies, pre }\end{array}$ & ion of malar & $\begin{array}{l}\text { death rate on } \\
\text { nd the } \\
\text { ficant at } 10 \% \text {, }\end{array}$ \\
\hline
\end{tabular}

